\title{
Research on School-Enterprise Cooperation Mode Innovation Based on Integration of Industry and Education
}

\author{
Lixin Ma ${ }^{a}$, Panpan Yuan \\ Institute of Light Engineering, Harbin University of Commerce, Harbin, China, 150028 \\ a13352502179@163.com, byuanpan1229@163.com
}

Keywords: integration of industry and education; school-enterprise cooperation; talent cultivation;

\begin{abstract}
With the development of higher education in China, different education modes are explored and school-enterprise cooperation has become a hot topic. Based on the specific case of Harbin University of Commerce, this paper introduces the background and main content of the school-enterprise cooperation mode. It takes the cooperative enterprise as an example to discuss main problems existing in the current cooperation mode. It also provides some suggestions about improving the school-enterprise cooperation mode and personnel training.
\end{abstract}

\section{Introduction}

The State Council has issued a talent training model for school-enterprise cooperation as early as 2002 and 2005, which was first implemented in the field of education. Although the "Skills + Education” Talent Training has achieved certain results, there are still some potential problems ${ }^{[1]}$. Developed countries have conducted researches on the mode of school-enterprise cooperation for many years. They have formed educational models with different characteristics. In the United States, students normally get into schools and focus on theory for half a year, then they participate in both the company internships and school lectures until half a year before they finally graduate when the school conducts centralized classroom to offer lectures so that the students could complete their thesis. Other developed countries have similar procedure, such as the UK's " $1+2+1$ ", " $1+3+1$ ", " $2+1+1$ " talent training model, and “dual system" in Germany ${ }^{[2]}$. In China, Delta Group has established cooperative relations with various universities in China, providing training venues and practice bases to train talents needed by enterprises. Combining the advanced school-enterprise cooperation experience at abroad with the national conditions of current education in China, the "order-based" school-enterprise cooperation model came into being ${ }^{[3]}$.

\section{School-Enterprise Cooperation Mode with Integration of Industry and Education}

Enterprises and colleges have established school-enterprise cooperation relationship in a variety of ways.

(1) "Order-based" cooperation mode: the most important part of economic revitalization is the revitalization of talents. In the increasingly fierce environment of market, enterprises have the clearest picture about the status and development trend of current industry, as well as the weakness of the students in terms of their ability and knowledge ${ }^{[4]}$. Under this cooperation mode, students are selected and then special skill classes are held for talents. In this way, they would be employed directly by the company after they graduate. With regular training before graduation, students not only get to know in advance some of the basic skills to work in those companies, but also the theoretical knowledge. Besides, they could also improve their ability to use various software. For example, deep understanding of hands-on analysis, ECRS principles, and 5S principles etc. in basic industrial engineering; and IE techniques such as $5 \mathrm{~W} 1 \mathrm{H}$, motion analysis, time research, program analysis, both hands method, human-machine coordination, and foolproof methods, illustrating with production line examples. These specific targeted exercises allow students to get excellent training before they enter the position. 
(2) Formulation and improvement of teaching materials: the formulation of teaching materials. In the school-enterprise cooperation, schools and enterprises are the main subjects. Whether the two parties can maintain the same decision-making and information sharing is the key to an efficient cooperation. The project management mode can be adopted in talent exchange ${ }^{[5]}$. The management personnel of the enterprise and the school will work together to formulate the student training plan, reasonably arrange the student's teaching progress, curriculum, training objectives and credits and examination requirements, and pay attention to the professional quality and ability while not neglecting the moral quality of the students, so as to realize comprehensive development of students. The project leader will set up an information exchange organization to supervise daily teaching and practical activities. At the same time, students will be guided and trained after entering the enterprise to cope with problems like being unfamiliar with the environment, not skilled enough, and lacking of maturity ${ }^{[6]}$. Strengthen the school-enterprise interaction in the "order-based" talent training model, that is, the company provides the internship base, equipment and raw materials; enterprises would participate in designing school's teaching plan and assigning professionals to participate in the school's professional teaching. Excellent managers or technicians of the enterprise will teach in the school and be instructors at the school. At the same time, they can continue to learn and update their professional knowledge thus promote mutual employment between the school and the enterprise. Engineers from the enterprise enter campus to teach the students, and the teachers train the employees and improve the quality of the staff while they could learn in the enterprise, enriching their practical experience and improving their practical ability ${ }^{[7]}$.

(3) Co-construction of the laboratory: adding enterprise elements in the construction of the laboratory and the experimental content, including the AC servo drive tester (as shown in Fig. 1), the Inverter tester (as shown in Fig. 2) and the modular controller (as shown in Fig. 3), is of great significance to the base declaration, project cooperation, promotion of teaching and improvement of teaching quality. Through the experiment, we can grasp the professional knowledge better and enhance the students' practical ability.

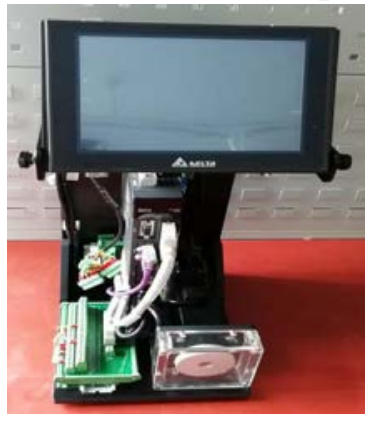

Figure 1. ASDA-A2 tester

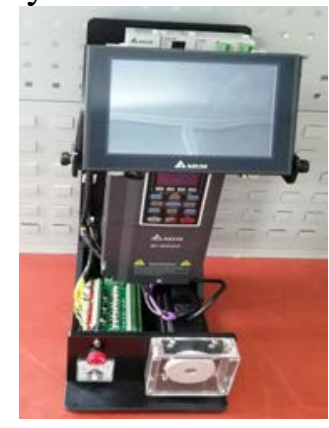

Figure 2. C2000 Tester

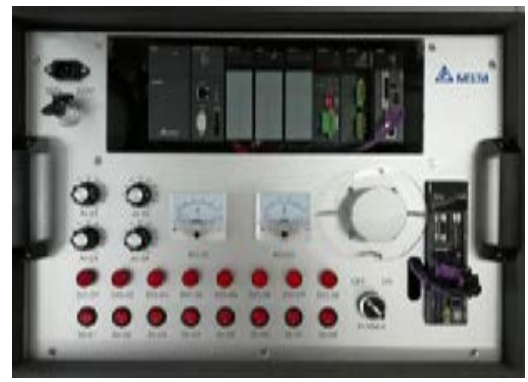

Figure 3. AH500 modular controller

C-Type workstation system involves industrial robots, intelligent vision systems, automatic control, position control, logistics technology, motor control, pneumatic control, programmable controllers, sensor applications, network communication and other technologies, almost covering automation control, computer application, logistics network communications, warehousing and logistics, and other professional fields, which have realized the sharing of resources in various majors of the school. See Fig. 4 for more details.

The establishment of laboratories by enterprises and schools can enhance the communication between the two and enhance mutual trust. At the same time, participation of enterprises in the process of laboratory establishment can improve the practicability and meet the requirements of production practice and needs of industry development. The pre-employment training is completed in advance, thus improves efficiency and reduces expenditure. By building a laboratory jointly, it will improve students' practical and innovative ability and enable the students to put theory into practice in time. In this way, students can receive training earlier before they get to work. All these make it a win-win situation for schools, enterprises and students. 


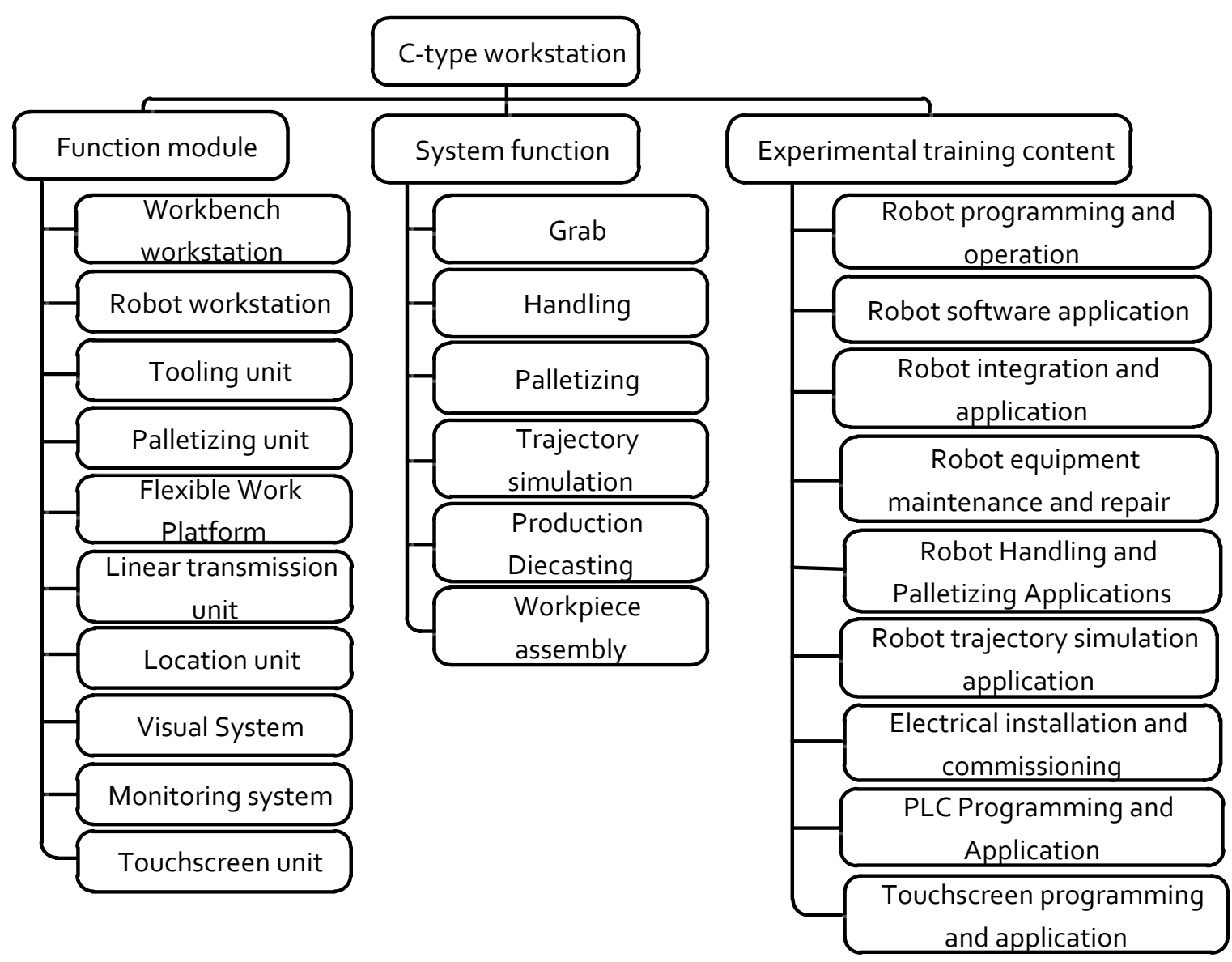

Figure 4 C-type workstation structure module and function

(4) Teacher training: teachers are an important factor affecting the cooperation between schools and enterprises. It is also a crucial problem to the current construction of colleges and universities. Teacher resource determines the level of cooperation between schools and enterprises. Whether the school can cultivate talents that meet the needs of social and enterprise development is directly affected by teacher resource. Therefore, it is necessary to bring in talents, improve the talent introduction mechanism, and improve teachers' conditions. Targeted training for teachers should be conducted, along with more opportunity to visit and learn from enterprises to meet requirements of teachers for the cooperation between schools and enterprises.

(5) Enterprise network teaching: Enterprises and schools provide online teaching resources jointly. In addition to studying at school and from teachers, students also need to participate in online teaching. With more systematic and targeted learning expertise and under the supervision of both enterprises and the school students could be more directly connected with the enterprise and improve professional quality. Teachers can observe each student in the classroom and interact with them from a distance.

(6) Integration of internship and graduation design: students can go to the company for visits and internships during the summer and winter vacations. Through practical experience, what they learn and practice can bring them insights for graduation design. Meanwhile the enterprise instructors can participate in the graduation guidance, which means that each student has two teachers from inside and outside the school to supervise their graduation design. Enterprise instructors can introduce new technologies, new techniques, new equipment and new materials in their subject areas, which helps broaden students' horizons, improve the quality of and enrich students' papers. Topic selection can be conducted with the combination of actual production and practical problems of the enterprise. This could enhance the students' ability to solve practice problems in engineering and their innovation ability, and at the same time, strengthen their awareness of the enterprise. 


\section{Main problems and measures in school-enterprise cooperation}

(1) Concentric collaboration: the level of understanding, importance and support of both the leaders of the schools and enterprises on the integration of production and education affects the success of cooperation directly. In the school-enterprise cooperation, project management should be realized, according to the school and the enterprise. The need for development, the realization of interdisciplinary and inter-departmental collaboration, the rational allocation of resources, the provision of technical support for the development of enterprises and the creation of conditions for the combination of theory and practice in various disciplines.

(2) Management mode: most universities are under pyramid-type management mode. Each department abides strictly by the rules and regulations of its own departments. The departments are relatively independent, which causes obstacles in communication and information sharing among them. At the same time, there are cross-sections among departments so that when there is a problem, the departments try to shift the responsibility to each other. In order to carry out the school-enterprise cooperation smoothly, it is necessary to reform the management mechanism of the colleges and universities. In other words, we need to integrate departments with overlapping duties, implement special management within the department, and realize information sharing and concentration of rights.

(3) Time conflict: time conflict between academic study in the school and internship and training in enterprises. Find ways to allocate time to theoretical study and actual skills according to individuals' needs. Deal with key issues including differences in students' levels, learning speed as well as differences in enterprises' needs.

(4) Assessment mechanism: off-campus credits are often treated unequally to credits in school. It is not only necessary to assess the students' theoretical study and grades in school, but also the practical skills and daily performance in the enterprise, so is the students' moral level at the enterprise and school to ensure the comprehensive development of students.

\section{Conclusion}

Innovation of school-enterprise cooperation mode is to cultivate students based on enterprises' requirements in knowledge, ability and quality of talents. Jointly, schools and enterprises develop training plans, conduct teaching and training, make the teaching objectives clearer, and reduce the blindness in teaching. Students are supposed to follow the company's requirements actively and take the initiative to learn. We need to explore innovative ideas and new modes of cooperation in the process of cultivating talents, to keep goals in teaching, internships and work consistent.

\section{References}

[1] Xiaoyan Liu,Ling Ding.China Journal of Commerce,2018(11):p.184-185.

[2] Lijian Qin, Xingxing Fei.Journal of Suihua University, 2018, 38(05):114-117.

[3] Zhiling Ren, Rui Guo.Chinese University Technology Transfer, 2018(05):54-55.

[4] Xun Wang, Yan Wang.Continue Education Research, 2018(05):55-58.

[5] Qian Zhou, Shuzhen Chen,Haiyan Wu. Business Economy,2018(05):184-185.

[6] Changqing Zhou.CO-Oerativeconomy \& Science, 2018(12):182-183.

[7] Tao Chen.Journal of the Chinese Society of Education, 2018(06):118. 